\title{
Survey of Members of the Indian Society of Labour Economics on the COVID-19 Crisis and Employment
}

\author{
Gerry Rodgers ${ }^{1}$
}

Published online: 23 September 2020

() Indian Socie of Labour Economics 2020

Beyond the immediate impact of the COVID-19 pandemic on health and mortality, there are major consequences for the labour market. But the information available on this impact is quite fragmented and often anecdotal. Many members of the Indian Society of Labour Economics (ISLE) have personal experience or knowledge of the impact of the crisis, or have local sources of information and research results, so they constitute an important pool of expertise on the labour market issues concerned.

An online survey of ISLE members was therefore carried out in the last week of May 2020 to ask for their assessments of the impact of the COVID-19 crisis and their views on the policies needed to overcome it, prior to the ILO-ISLE-IHD virtual conference held on 8-9 June. The questionnaire is given in the supplementary material. ${ }^{1}$

520 valid responses were received.

The first series of questions concerned the views of ISLE members as to the groups which have been most affected by the crisis, in terms of employment and income, in the state of residence of the respondents. Respondents were invited to identify the group of the population most affected within the categories of age, sex, caste, location and migrant status. Figure 1 shows the per cent of respondents choosing each group.

The great majority of respondents thought that the middle age groups, aged $30-59$, had been most affected. Less than $20 \%$ thought that younger people were

\footnotetext{
${ }^{1}$ This survey was implemented by IHD team led by Balwant Mehta, who also organized the data processing. The survey was carried out as background for the ILO-ISLE-IHD Conference on the implications of the COVID-19 crisis for labour and employment in India, June 8-9, 2020. The design of the questionnaire reflects contributions by Alakh N. Sharma, Ravi Srivastava, Dev Nathan and J. Krishnamurty as well as the author. Technical and organizational support was provided by Priyanka Tyagi. We would like to thank the many ISLE members who took the time to answer the questionnaire and give their views.
}

Electronic supplementary material The online version of this article (https://doi.org/10.1007/s4102 7-020-00275-w) contains supplementary material, which is available to authorized users.

Gerry Rodgers

gerry.rodgers@cantab.net

1 Institute for Human Development, New Delhi, India 


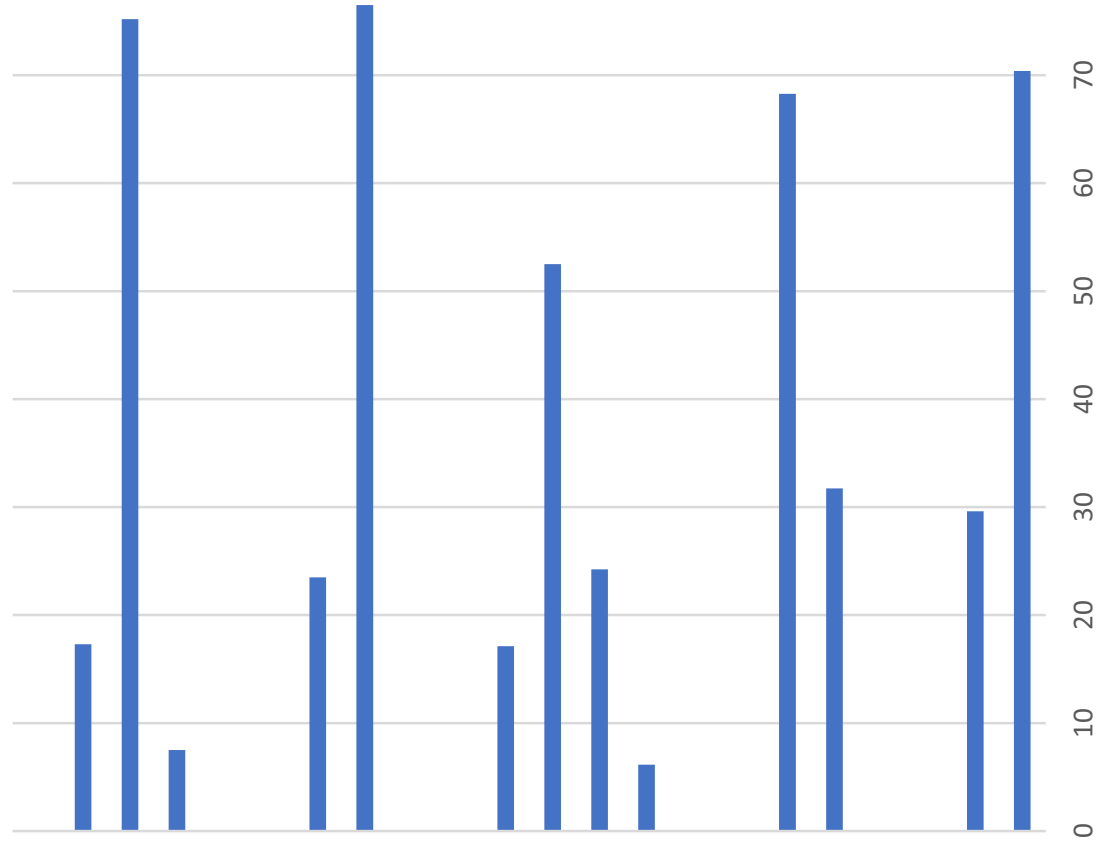

ㅇ

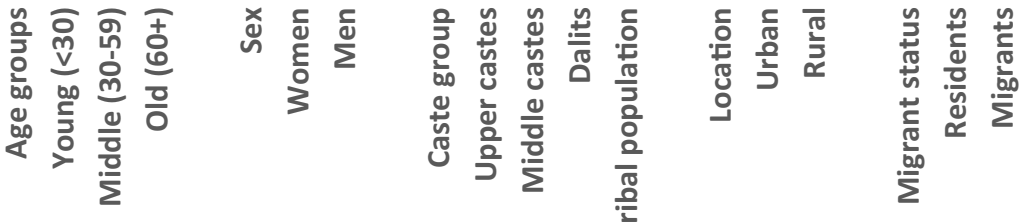


most affected and less than $10 \%$ identified older people. This refers to employment and income-obviously older groups are more vulnerable to the disease itself.

A large majority thought that men were more affected (76\%) than women (24\%). However, amongst female respondents to the questionnaire, only 59\% thought that men were more affected, whereas amongst male respondents, $89 \%$ thought that men were more affected. So there is a large gender difference in the perception of the impact.

In terms of caste groups, a majority thought that middle castes were most affected. Dalits were second, some way behind.

Large majorities thought that the urban population was more affected than rural, and migrants more than residents.

Figure 2 gives similar results for different groups of workers. The majority view was that the unskilled were more affected than the skilled; wage workers more than the self-employed; and contract and casual workers more than permanent workers. Views on the impact by branch of activity were more divided. About half of the respondents thought that workers in industry and construction were most affected, but this sector was closely followed by trade and services. Very few respondents thought that agriculture had been most affected.

The answers to these questions did not vary much across regions of the country (North, East, South and West). There were some differences in the perceived caste impact (respondents from the North of the country thought that there was a larger impact on Dalits than respondents from other regions, for instance). Respondents from the South gave greater importance to the impact on migrant wage workers. But the general pattern of the answers was the same everywhere.

Female respondents tended to give greater importance to the impact on migrants and the unorganized sector.

The next question asked was how long there will be disruption to employment and incomes. Almost half thought that it would last more than 1 year, just under $30 \%$ chose 1 year, and less than a quarter thought that the disruption would last for 6 months.

Respondents were then asked to choose the three most important impacts of the crisis in their state of residence, apart from the direct effect on health and mortality (Fig. 3). Loss of employment was by far the most important, chosen by more than $90 \%$ of respondents. Loss of production was identified by almost $40 \%$ and closure of businesses by almost 30\%. Moreover, $40 \%$ focussed on hunger and food shortage, but about the same number highlighted the growth of inequality. Family impacts, including violence against women and child labour, were given less importance, and this was true of both male and female respondents.

Next, respondents were asked to select three from a list of policy priorities in the coming months (Fig. 4). Protection of workers and families came top, identified by more than two-thirds of respondents. That included protective measures in the workplace such as masks, social distancing and disinfection of work sites. Not far behind came short term employment creation (over 60\%) and income transfers for affected workers (over 50\%). A series of other measures were identified by $30-40 \%$ of respondents, including on the production side increased support for agriculture and small business, and on the welfare side better food distribution and housing and 


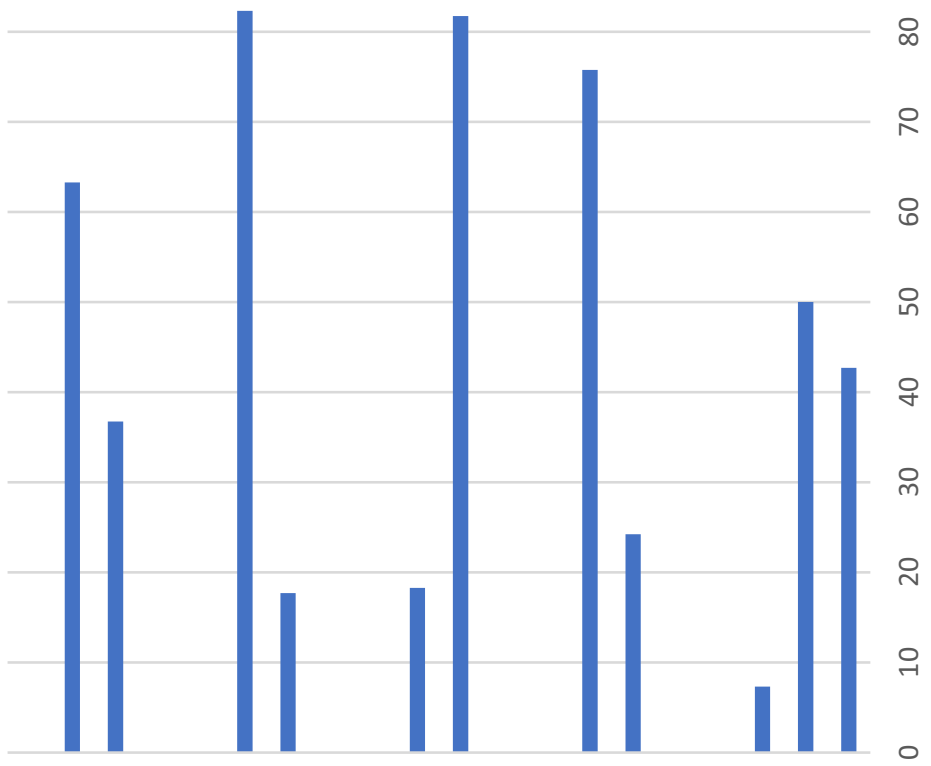

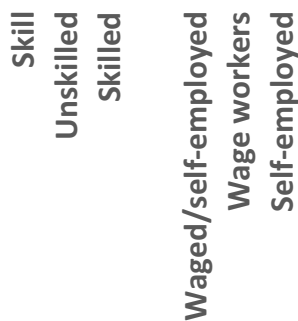

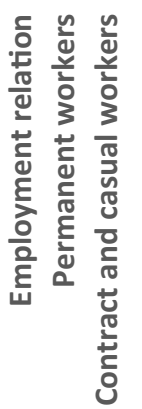

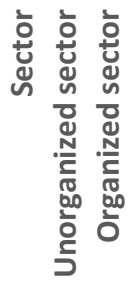

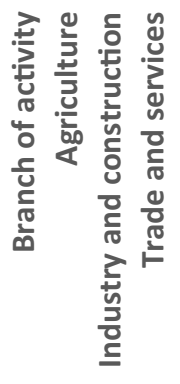

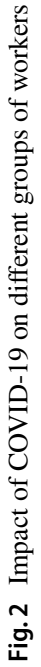




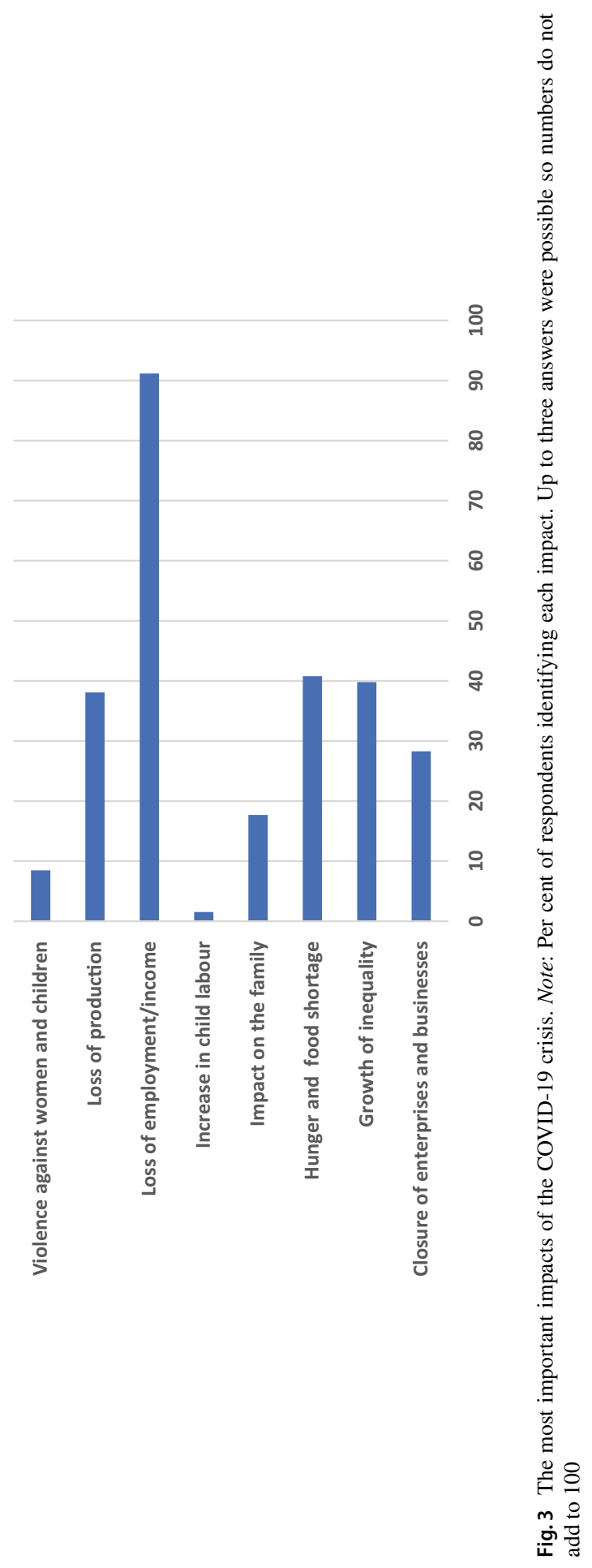




0
0
0
0
0
8
0
0
0
0
0
0

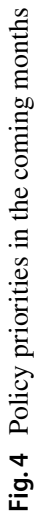


care policies for migrant workers. Only loans and subsidies for large businesses did not receive significant support.

In addition to choosing priorities from this list, respondents were invited to suggest additional priorities. There are many suggestions, which have been grouped into a number of categories in Fig..$^{2}$ A majority of these suggestions were in reality further development of issues already included in the original list (Fig. 4). This was particularly true of the priority given to micro, small and medium enterprises, job creation through MGNREGA, cash transfers, food distribution, welfare policies for migrants and support for agriculture. Other suggestions with substantial support included a push for infrastructure and construction, a strengthening of health infrastructure and (to a lesser extent) empowering of local government.

Differences between regions of the country in the priorities for policy were small.

A final question on current policies asked whether the current division of responsibilities between Centre and States was right. Only $20 \%$ of respondents thought that it was about right, and almost $70 \%$ thought that there should be more responsibilities and resources devolved to the States.

Respondents were then asked about the long-term impact of the crisis (Fig. 6). There was a widespread expectation of lower economic growth in the long term. But, in addition, more than half of the respondents expected a rise in inequality. Almost, as many expected that there would be a reorganization of employment such as a growth of teleworking and the gig economy, and many expected disruptions in supply chains. More than a third of respondents also anticipated a rise in public debt and consequent austerity policies, but less than one-third anticipated increased support for social security, and not much more than $10 \%$ expected better organization of workers.

Finally, respondents were asked to indicate the most important policies for the future, selecting up to five from a list (Fig. 7). Top was an improved public health system, identified by over $75 \%$ of respondents. Three other policy areas were selected by more than $50 \%$ of respondents: universalization of social security, stronger policies for the welfare and rights of migrants, and an expansion of MGNREGA, including urban areas.

In addition to the universalization of social security, there were two more specific social security measures in the list-universal basic income, and unemployment insurance. Both received substantial support, so overall the priority was clearly for a much larger investment in social security and social protection, even if there were differing views on the type of social security needed. But whilst many respondents thought that universal social security in some form was needed, less than one-third of respondents thought that there would be increased public support for this after the crisis (third line in Fig. 6).

Several labour market measures had support from around $20 \%$ of respondentsbetter labour market information, more training, better regulation of employment relations and action against discrimination. Altogether they amount to a strong case

\footnotetext{
2 This is a rather approximate procedure, since many suggestions cut across categories or needed to be interpreted. The graph just gives an idea of the pattern.
} 

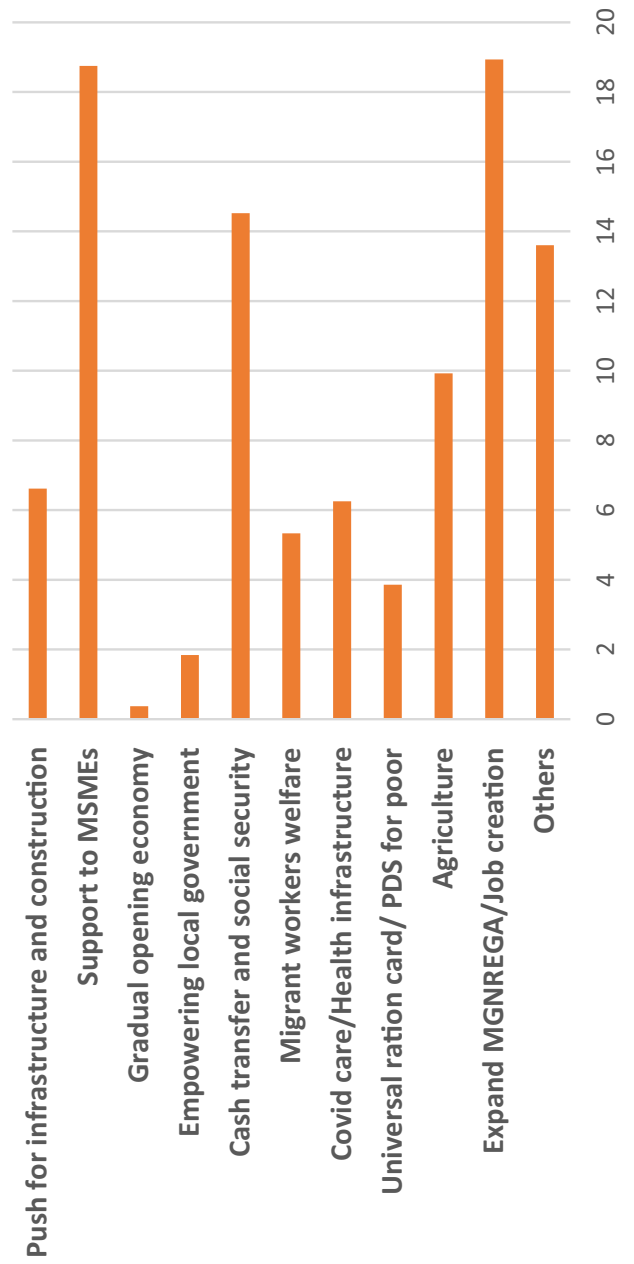

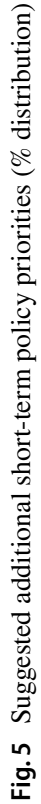




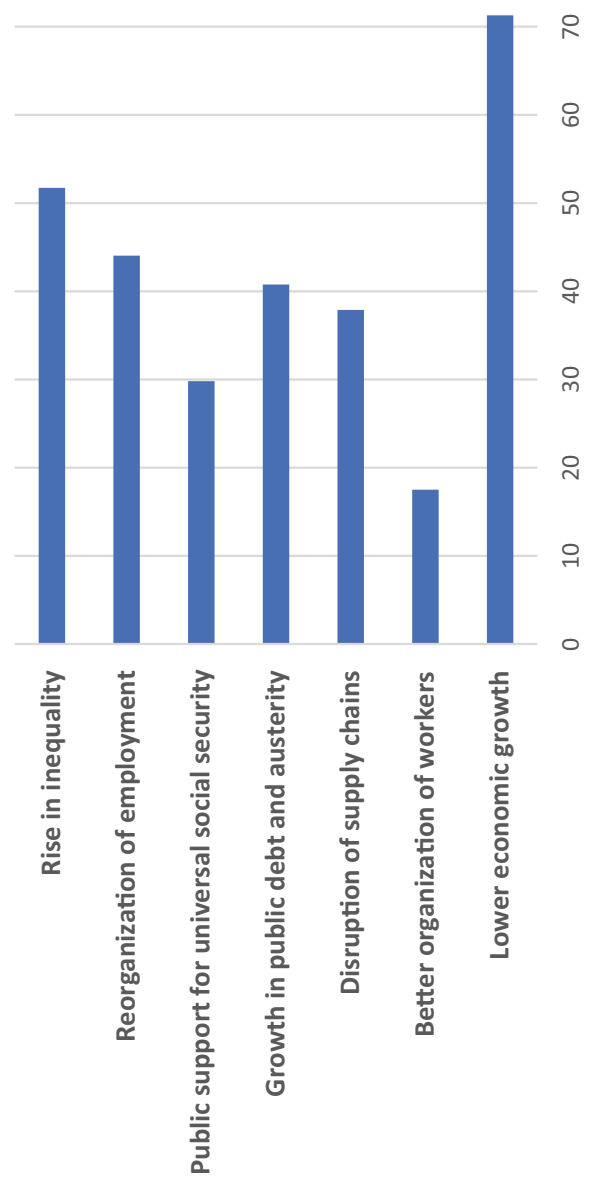

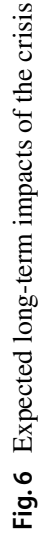




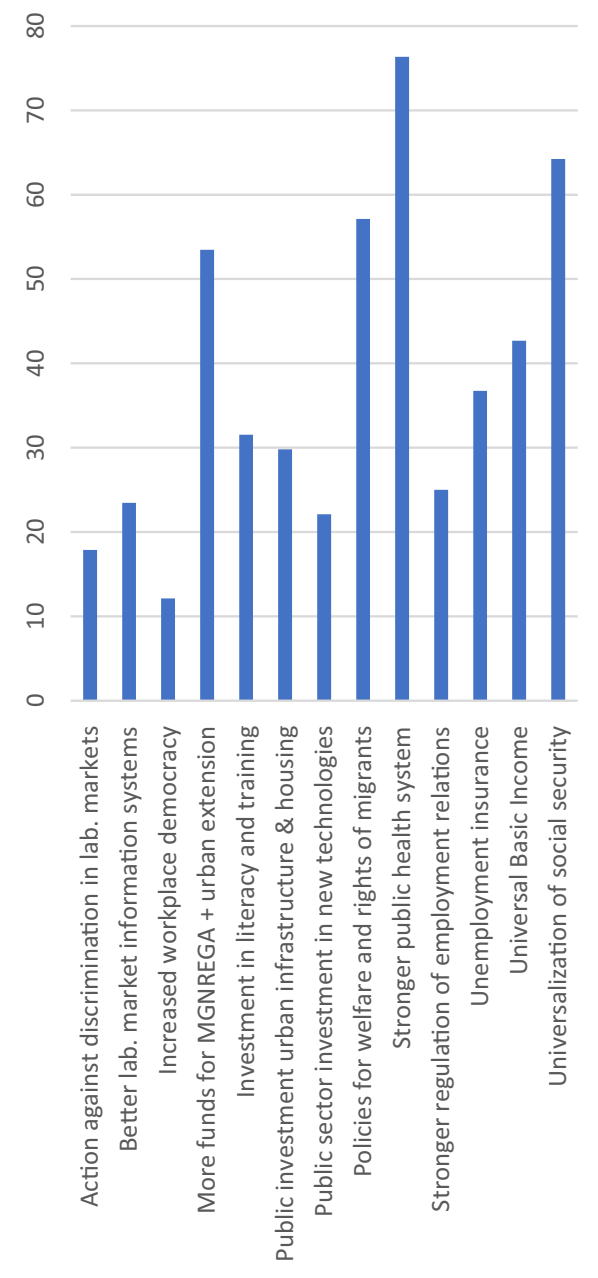

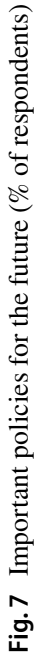




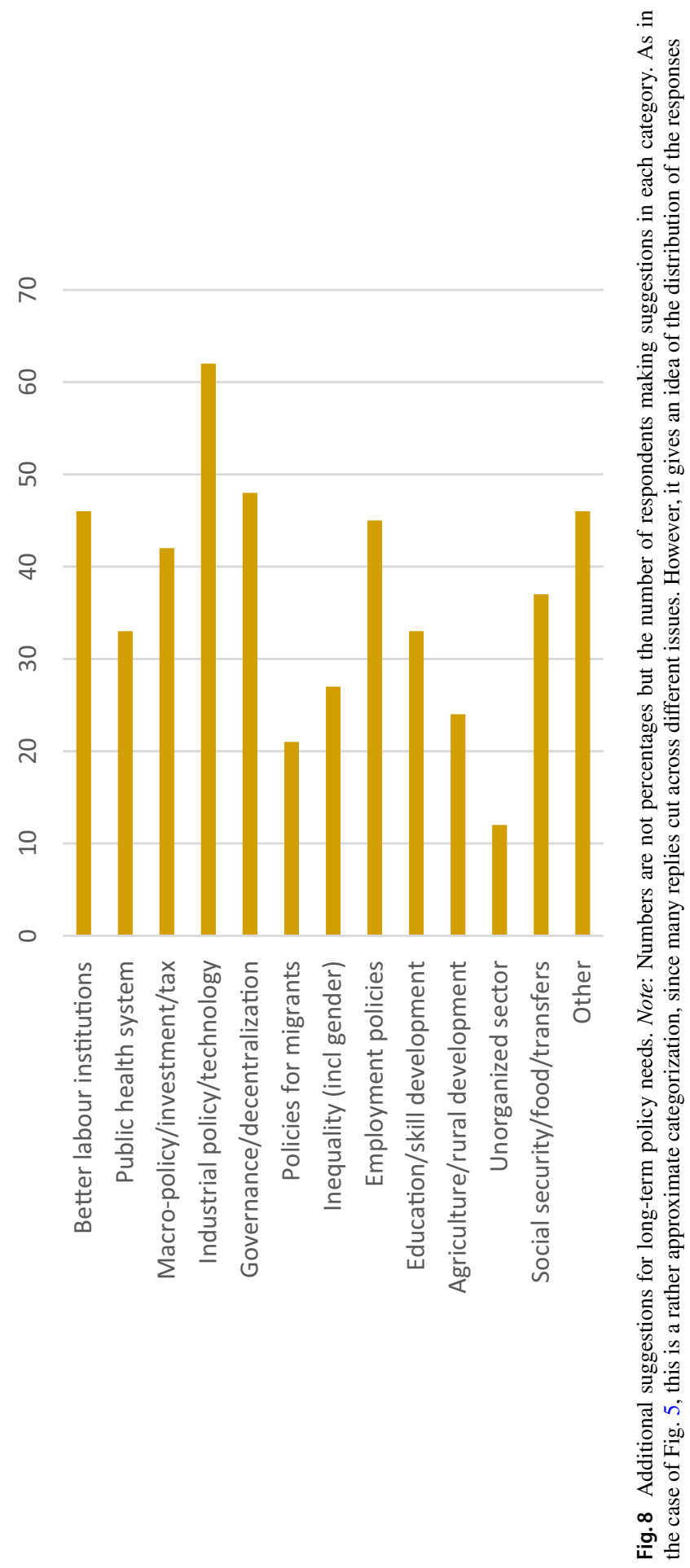


for stronger and better labour market policies as an important part of the response to the crisis. There was less support for greater workplace democracy. Finally, greater public investment in urban infrastructure, low cost housing and new technologies received significant support.

There were some significant differences between regions in the longer term priorities. In the South of the country, there was greater emphasis on workplace democracy, better labour market information, more funds for MGNREGA and the rights of migrants. There was correspondingly less emphasis on improved social security, which was given higher priority in other parts of the country. But the regional differences are again smaller than one might have expected.

Respondents were also invited to write in additional suggestions for long term policies. There was a wide range of suggestions. Fig. 8 summarizes the main areas in which policy suggestions were made. There were many. Employment, social security, public health, labour market institutions and the situation of migrants were emphasised again, and there were additional ideas for industrial policy (including technology policy and support to small firms), skill development, reduction in inequality (including gender inequality), rural development, and macro-economic policy. Many respondents highlighted a need for better governance and more decentralization, both to States and to local communities.

Many of these issues were on the agenda of the conference, and are discussed further in the notes and articles provided by speakers and included in this issue of the IJLE.

Publisher's Note Springer Nature remains neutral with regard to jurisdictional claims in published maps and institutional affiliations. 